\title{
Optical coherence tomography evaluation of retinal nerve fiber layer in longitudinally extensive transverse myelitis
}

\author{
Frederico C. Moura', Danilo B. Fernandes', Samira L. Apóstolos-Pereira², \\ Dagoberto Callegaro², Paulo E. Marchiori², Mário L.R. Monteiro'
}

\begin{abstract}
Objective: To compare optical coherence tomography (OCT) measurements on the retinal nerve fiber layer (RNFL) of healthy controls and patients with longitudinally extensive transverse myelitis (LETM) without previous optic neuritis. Method: Twenty-six eyes from 26 patients with LETM and 26 control eyes were subjected to automated perimetry and OCT for comparison of RNFL measurements. Results: The mean deviation values from perimetry were significantly lower in patients with LETM than in controls $(p<0.0001)$. RNFL measurements in the nasal quadrant and in the 3-o'clock segment were significantly smaller in LETM eyes than in controls. ( $p=0.04$ and $p=0.006$, respectively). No significantly differences in other RNFL measurements were found. Conclusion: Patients with LETM may present localized RNFL loss, particularly on the nasal side of the optic disc, associated with slight visual field defects, even in the absence of previous episodes of optic neuritis. These findings emphasize the fact that patients with LETM may experience attacks of subclinical optic nerve damage.
\end{abstract}

Key words: tomography, optical coherence, transverse myelitis, neuromyelitis optica, multiple sclerosis.

Avaliação da camada de fibras nervosas da retina na mielite transversal longitudinalmente extensa usando tomografia de coerência óptica

\section{RESUMO}

Objetivo: Comparar as medidas da camada de fibras nervosas da retina (CFNR) usando a tomografia de coerência óptica (TCO) em indivíduos normais e pacientes com mielite transversal longitudinalmente extensa (MTLE) sem episódio prévio de neurite óptica. Método: Vinte e seis olhos de 26 pacientes com MTLE e 26 olhos normais foram submetidos à campimetria computadorizada e TCO para comparação das medidas da CFNR. Resultados: Valores do parâmetro desvio médio da campimetria computadorizada

Correspondence Frederico Castelo Moura Rua Pedroso Alvarenga 1077 04531-012 São Paulo SP - Brasil E-mail:fredcastelo@usp.br

\section{Support}

By grants from Fundação de Amparo a Pesquisa do Estado de São Paulo FAPESP (No. 2009/50174-0), São Paulo, Brazil, and from Conselho Nacional de Desenvolvimento Científico e Tecnológico, CNPq (No. 309709/2007-5), Brasília, Brazil

Received 3 June 2010

Received in final form 3 August 2010 Accepted 10 August 2010 foram significativamente menores nos pacientes com MTLE do que nos controles $(p<0,001)$. Medidas da CFNR no quadrante nasal e no segmento 3 horas foram significativamente menores nos olhos dos pacientes com MTLE do que nos olhos normais ( $p=0,04$ e $p=0,006$, respectivamente). Não foi encontrada diferença significante nas outras medidas da CFNR avaliadas. Conclusão: Pacientes com MTLE podem apresentar perda localizada da CFNR, particularmente na região nasal do disco óptico, associada a defeitos discretos de campo visual, mesmo na ausência de episódio prévio de neurite óptica. Estes achados sugerem que pacientes com MTLE podem apresentar acometimento subclínico do nervo óptico. Palavras-chave: tomografia de coerência óptica, mielite transversa, neuromielite óptica, esclerose múltipla.

${ }^{1}$ Division of Ophthalmology and Laboratory of Ophthalmological Investigations (LIM 33), University of São Paulo Medical School, São Paulo SP, Brazil; ${ }^{2}$ Department of Neurology, University of São Paulo Medical School, São Paulo SP, Brazil. 
Acute transversal myelitis (ATM) is a disease characterized clinically by acute neurological dysfunction in motor, sensory and autonomic nerves and tracts of the spinal cord. Systemic diseases, ischemic events, infections and demyelinating processes are the major etiologies, while $16 \%$ have been referred to as idiopathic ${ }^{1}$. When fewer than two vertebral segments are involved, as seen on magnetic resonance imaging, the risk of developing multiple sclerosis (MS) is high. However, when three or more vertebral segments are affected, which is a condition known as longitudinally extensive transverse myelitis (LETM) $)^{2}$, the risk of MS is low. LETM has a poorer prognosis and a higher risk of relapse, and is strongly associated with neuromyelitis optica (NMO). In fact, some authors consider ATM and LETM to be components of a single spectrum of disease ${ }^{3-5}$. In one study, NMO-IgG autoantibodies were detected in $52 \%{ }^{6}$ of the patients with recurrent LETM and in $40 \%$ of the patients with a single episode of LETM ${ }^{4}$. The prognosis is worse for NMO than for MS and, since the treatment is currently different for these two conditions, early distinction of MS from NMOrelated disorders is of great importance ${ }^{6,7}$.

Optical coherence tomography (OCT) is a noninvasive technique that can detect retinal nerve fiber layer (RNFL) thickness abnormalities in different types of anterior optic pathway diseases ${ }^{8-14}$. Axonal loss can also be estimated by measuring the decrease in macular thickness and volume caused by loss of retinal ganglion cell bodies that is induced by permanent axonal damage ${ }^{9}$. In previous studies, OCT scanning revealed axonal loss in MS patients both with and without previous optic neuritis $(\mathrm{ON})$, thus suggesting that $\mathrm{OCT}$ can detect subclinical optic nerve demyelination in such patients ${ }^{15,16}$. The technique has also been used to detect axonal loss in patients affected with $\mathrm{NMO}^{14,17}$.

Recently, Ratchford et al. ${ }^{17}$ evaluated average macular volume and RNFL thickness around the optic disc using OCT in patients with MS, NMO and LETM with and without previous episodes of ON. A significant difference was found between measurements on controls and 338 non-ON eyes, indicating subclinical involvement in the latter group. No difference was found between controls and 17 non-ON eyes of patients with LETM or 8 non-ON eyes of patients with NMO. The authors suggested using OCT to help differentiate NMO from MS. Focal RNFL loss was not investigated.

In addition to measuring average (360-degree) RNFL thickness, current OCT versions can provide separate thickness measurements for each of the four quadrants and for twelve 30-degree segments around the optic disc, thereby increasing the chances of detecting subclinical axonal loss. The purpose of this study was to evaluate average, quadrantic and segmental RNFL thickness mea- surements using OCT in 26 patients with idiopathic LETM without previous episodes of ON, in order to investigate possible occurrences of subclinical, diffuse or localized involvement of the optic nerve in these patients.

\section{METHOD}

\section{Study design and sampling}

This was an observational, prospective cross-sectional study. Participants were recruited from the Department of Neurology of the University of São Paulo Medical School. Approval from the Institutional Review Board Ethics Committee was obtained for the study. The study followed the principles of the Declaration of Helsinki and informed consent was obtained from all participants.

A total of 26 eyes from 26 patients (19 females) with idiopathic LETM without any previous episodes of optic neuritis and 26 eyes from 26 normal age-matched controls (19 females) were studied. All subjects were subjected to a complete ophthalmological examination including standard automated perimetry (SAP) using the 24-2 SITA-standard strategy (Humphrey Field Analyzer, Carl Zeiss Meditec, Dublin, CA, USA). Visual field (VF) and OCT examinations were performed on the same day or within a maximum period of one week.

The neurological inclusion criteria for the study were occurrences of monophasic sensory, motor or autonomic dysfunction that were attributable to the spinal cord, with bilateral signs or symptoms and progression to nadir taking between 4 hours and 21 days, inflammation within the spinal cord demonstrated by cerebrospinal fluid (CSF) pleocytosis or elevated IgG index or gadolinium enhancement on MRI, and spinal cord MRI abnormality involving three or more vertebral segments. The neurological exclusion criteria were extra-axial compressive etiology seen through neuroimaging, history of radiation to the spinal cord within the last 10 years, central nervous system (CNS) manifestation of infectious diseases (including syphilis, Lyme disease or viral infection), serological and clinical evidence of connective tissue disease, brain MRI abnormalities suggestive of MS or acute disseminated encephalomyelitis, and previous episodes of ATM.

The ophthalmological inclusion criteria for the study were best corrected visual acuity of $20 / 25$ or better in both eyes, spherical refraction within $\pm 5 \mathrm{D}$ and cylinder refraction within $\pm 4 \mathrm{D}$, intraocular pressure $<22 \mathrm{mmHg}$, and reliable VF. A reliable Humphrey VF test was defined as one with fewer than 33\% fixation losses, false positive responses or false negative responses. The ophthalmological exclusion criteria were histories of clinically apparent optic neuritis or other optic neuropathies, histories of intraocular pressure elevation, clinical signs of glaucomatous optic neuropathy, and optic disc anomaly. In one patient, only one eye met the inclusion criteria. For the 25 
patients in whom both eyes fulfilled the inclusion criteria, one eye was randomly selected for analysis.

The possibility of visual dysfunction in LETM patients was evaluated using the mean deviation (MD) of SAP. The control group consisted of normal healthy volunteers recruited from among the hospital staff. All the control subjects had a normal ophthalmic examination and SAP visual field. Only one eye from each healthy subject was included in the analysis, and selection between the right and left eye was performed such that it matched the selection in the patients with LETM.

\section{Optical coherence tomography}

The subjects underwent ocular imaging with dilated pupils using commercially available OCT equipment (Stratus-OCT, Carl Zeiss Meditec Inc., Dublin, CA, USA). The OCT scanning protocol has been described in detail elsewhere ${ }^{9}$. RNFL thickness was measured using the "fast RNFL thickness protocol". Peripapillary RNFL thickness parameters were automatically calculated using the Stratus-OCT software (version 4.0.1). The RNFL thickness parameters evaluated in this study were the 360-degree average, the temporal quadrant (316-
45 degrees), superior quadrant (46-135 degrees), nasal quadrant (136-225 degrees) and inferior quadrant (226315 degrees), and each of the twelve 30-degree segments (with the 3-o'clock position as nasal). Image quality was assessed by an experienced examiner. Good-quality scans had to have focused images and signal strength greater than or equal to 7 , and presence of the circular scan centered on the optic disc.

\section{Statistical analysis}

The LETM eyes and control eyes were compared with regard to RNFL thickness parameters and SAP MD values using Student's t test. Histogram analysis and the Shapiro-Wilk test confirmed that the distributions satisfied the normality assumption. Receiver operating characteristic (ROC) curves were used to describe the ability of Stratus OCT parameters to discriminate between the eyes of patients with LETM and the eyes of healthy subjects. P values less than 0.05 were considered statistically significant.

\section{RESULTS}

A total of 26 eyes from 26 patients with idiopathic LETM under investigation for NMO and without previ-

Table. Mean retinal nerve fiber layer thickness $(\mu \mathrm{m}) \pm$ standard deviation, and area under receiver operating characteristic curves (AUC), for 26 eyes from patients with longitudinally extensive transverse myelitis (LETM) and 26 eyes from normal controls.

\begin{tabular}{lcccc}
\hline & LETM $(\mathrm{n}=26)$ & Control $(\mathrm{n}=26)$ & $\mathrm{P}$ & AUC (SD) \\
\hline Average & $100.58 \pm 12.56$ & $105.55 \pm 9.18$ & 0.11 & $0.60(0.07)$ \\
Quadrants & & & & \\
Superior & $124.12 \pm 21.16$ & $130.35 \pm 13.78$ & 0.21 & $0.59(0.08)$ \\
Nasal & $73.85 \pm 15.03$ & $82.46 \pm 14.42$ & 0.04 & $0.65(0.08)$ \\
Inferior & $134.42 \pm 20.47$ & $137.12 \pm 20.89$ & 0.64 & $0.54(0.07)$ \\
Temporal & $70.08 \pm 11.55$ & $72.27 \pm 14.55$ & 0.55 & $0.53(0.08)$ \\
Clock hours & & & & \\
12 o'clock & $127.04 \pm 31.42$ & $136.85 \pm 23.04$ & 0.21 & $0.64(0.07)$ \\
1 o'clock & $116.85 \pm 29.01$ & $122.12 \pm 20.82$ & 0.45 & $0.55(0.08)$ \\
2 o'clock & $88.73 \pm 20.14$ & $99.81 \pm 22.16$ & 0.06 & $0.69(0.07)$ \\
3 o'clock & $55.65 \pm 12.99$ & $67.62 \pm 16.53$ & 0.006 & $0.72(0.07)$ \\
4 o'clock & $73.15 \pm 16.86$ & $77.81 \pm 15.76$ & 0.31 & $0.59(0.08)$ \\
5 o'clock & $120.77 \pm 23.26$ & $124.58 \pm 21.57$ & 0.54 & $0.53(0.08)$ \\
6 o'clock & $144.81 \pm 30.37$ & $152.98 \pm 25.09$ & 0.33 & $0.58(0.08)$ \\
7 o'clock & $137.38 \pm 23.93$ & $138.27 \pm 25.13$ & 0.89 & $0.47(0.08)$ \\
8 o'clock & $73.08 \pm 17.94$ & $72.58 \pm 13.82$ & 0.91 & $0.50(0.08)$ \\
9 o'clock & $56.54 \pm 11.05$ & $57.23 \pm 8.54$ & 0.81 & $0.51(0.08)$ \\
10 o'clock & $84.38 \pm 15.45$ & $86.69 \pm 14.58$ & 0.58 & $0.53(0.08)$ \\
11 o'clock & $124.85 \pm 30.64$ & $134.27 \pm 16.03$ & 0.17 & $0.57(0.08)$ \\
\hline
\end{tabular}

LETM: Iongitudinally extensive transversal myelitis; AUC: area under receiver operating characteristic (ROC) curve. *Significant values are in italics. 
ous episodes of optic neuritis, and 26 eyes from 26 control individuals were studied. The mean age \pm standard deviation (SD) was $38.01 \pm 12.34$ years (range: $18-65$ ) in the LETM group and $30.01 \pm 12.06$ years (range: $18-62$ ) in the control group ( $\mathrm{p}=0.96$; Student's $\mathrm{t}$ test). On SAP, the VF mean deviation (MD) for LETM eyes and control eyes was $-2.51 \pm 1.15$ decibels $(\mathrm{dB})$ (range: -4.43 to $-0.57 \mathrm{~dB}$ ) and $-0.97 \pm 1.38 \mathrm{~dB}$ (range: -2.98 to $1.13 \mathrm{~dB} ; \mathrm{p}<0.0001$ ), respectively.

The table shows RNFL thickness measurements for the two groups and AUC values. The RNFL thickness measurements in the nasal quadrant and in the 3-o'clock segment were significantly smaller in LETM eyes than in controls ( $\mathrm{p}=0.04$ and $\mathrm{p}=0.006$, respectively). No other quadrant or segment of the optic disc presented any significant difference. The 3-o'clock segment yielded the highest AUC value (0.73; $\mathrm{p}=0.01)$.

\section{DISCUSSION}

NMO, also known Devic's disease, is a severe idiopathic inflammatory demyelinating disease defined by attacks of ATM and ON, and it most often results in bilateral blindness, paraplegia or quadriplegia ${ }^{18}$. Idiopathic LETM has a similar clinical presentation, with seemingly NMO-related myelitis, but without evidence of $\mathrm{ON}^{4}$. Since NMO-related neural damage includes not only demyelination but also axonal loss and extensive necrosis with progressive and extremely severe course, early diagnosis and treatment are of fundamental importance for preventing severe neurological deficits. The differentiation of NMO from multiple sclerosis is also of great importance. The fact that several studies ${ }^{19-21}$ have shown that patients with NMO present a better response to early therapy with immunosuppressive drugs than to therapy with immunomodulating agents emphasizes the importance of an early and accurate diagnosis.

Previous studies have demonstrated that OCT is a useful tool for diagnosing and following up several conditions that cause anterior optic pathway damage, including inflammatory and demyelinating diseases ${ }^{8-12,22-24}$. OCT has also been proposed as a biomarker for MS and as an aid for monitoring disease progression and treatment response $^{23,25,26}$. Studies using OCT have also shown a significant reduction of RNFL thickness in ON eyes of patients with NMO and MS, compared with normal eyes ${ }^{14,17,27}$. This reduction is greater in NMO eyes than in MS eyes, thus suggesting that optic nerve damage is more severe in the former ${ }^{17,27}$.

While axonal loss in eyes affected with $\mathrm{ON}$ is an expected finding, the subclinical axonal loss on OCT in eyes of patients with relapsing-remitting MS without a previous history of $\mathrm{ON}$ that has been observed in several studies $^{8,15,28,29}$ is somewhat more surprising. This is an impor- tant finding, because unaffected eyes of patients with relapsing-remitting MS may be evaluated very differently from the eyes of patients with LETM or NMO. Only two studies on unaffected eyes of patients with LETM and NMO have been published so far. Ratchford et al. ${ }^{17}$ confirmed that OCT can detect retinal abnormalities in patients with MS without previous ON, but did not find any significant reduction in the RNFL thickness of unaffected eyes of patients with "definite NMO" or LETM. These authors concluded that their findings were consistent with the observation that patients with NMO rarely convert to a secondary progressive course and that disability in NMO primarily results from relapses, whereas in MS, disability may result either from inflammatory relapses or from slowly progressive axonal degeneration, thereby leading to subclinical axonal damage. They also suggested that OCT measurements could help differentiate unaffected eyes of patients with LETM or NMO from those of patients with MS. However, they only compared average RNFL thickness measurements and their sample of NMO or LETM patients with unaffected eyes was relatively small (8 and 17, respectively). Likewise, de Seze et al. ${ }^{14}$ did not find any subclinical RNFL loss in the eyes of patients with extensive myelitis who were positive for anti-NMO antibodies. The study evaluated average and quadrantic RNFL thickness measurements, but the sample included only eight unaffected eyes of four myelitis patients.

In the present study, LETM patients with no history of ON were evaluated using OCT for possible subclinical optic nerve involvement. In contrast with the two studies discussed above ${ }^{14,17}$, the RNFL thickness in the nasal quadrant and the 3-o'clock segment was found to be significantly smaller in LETM eyes than in control eyes. Our findings suggest that subclinical damage is possible in LETM and that it occurs as focal rather than generalized axonal loss. The differences between our study and previous studies may be partly explained by limitations in study parameters ${ }^{17}$ or sample size $\mathrm{e}^{14}$. In conclusion, by measuring and comparing the RNFL thickness of each quadrant and 30-degree segment of a relatively large sample of eyes, we were able to detect localized neural loss that might have remained undetected if only the average (360-degree) thickness measurements had been used.

Importantly, our results show that patients with LETM can be affected by subclinical ON associated with focal RNFL loss. Therefore, RNFL measurements using OCT could potentially be used to identify subclinical axonal damage in patients with idiopathic LETM before episodes of optic neuritis occur. However, longitudinal studies with larger samples are required in order to fully explore the potential uses of OCT for evaluations on patients with NMO and idiopathic LETM. 


\section{REFERENCES}

1. de Seze J, Lanctin C, Lebrun C, et al. Idiopathic acute transverse myelitis: application of the recent diagnostic criteria. Neurology 2005;65: 1950-1953

2. Scott TF, Bhagavatula K, Snyder PJ, Chieffe C. Transverse myelitis. Comparison with spinal cord presentations of multiple sclerosis. Neurology 1998; 50:429-433.

3. Scott TF. Nosology of idiopathic transverse myelitis syndromes. Acta Neurol Scand 2007;115:371-376.

4. Weinshenker BG, Wingerchuk DM, Vukusic S, et al. Neuromyelitis optica IgG predicts relapse after longitudinally extensive transverse myelitis. Ann Neurol 2006;59:566-569.

5. Transverse Myelitis Consortium Working Group. Proposed diagnostic criteria and nosology of acute transverse myelitis. Neurology 2002:59:499-505.

6. Lennon VA, Wingerchuk DM, Kryzer TJ, et al. A serum autoantibody marker of neuromyelitis optica: distinction from multiple sclerosis. Lancet 2004;364: 2106-2112.

7. Matiello M, Lennon VA, Jacob A, et al. NMO-lgG predicts the outcome of recurrent optic neuritis. Neurology 2008:70:2197-2200.

8. Fisher JB, Jacobs DA, Markowitz CE, et al. Relation of visual function to ret inal nerve fiber layer thickness in multiple sclerosis. Ophthalmology 2006; 113:324-332

9. Moura FC, Medeiros FA, Monteiro ML. Evaluation of macular thickness measurements for detection of band atrophy of the optic nerve using optical coherence tomography. Ophthalmology 2007;114:175-181.

10. Monteiro ML, Cunha LP, Costa-Cunha LV, Maia OO, Jr., Oyamada MK. Relationship between optical coherence tomography, pattern electroretinogram and automated perimetry in eyes with temporal hemianopia from chiasmal compression. Invest Ophthalmol Vis Sci 2009;50:3535-3541.

11. Contreras I, Rebolleda G, Noval S, Munoz-Negrete FJ. Optic disc evaluation by optical coherence tomography in nonarteritic anterior ischemic optic neuropathy. Invest Ophthalmol Vis Sci 2007:48:4087-4092.

12. Kusuhara S, Nakamura M, Nagai-Kusuhara A, Nakanishi Y, Kanamori A, Neg A. Macular thickness reduction in eyes with unilateral optic atrophy detected with optical coherence tomography. Eye (Lond) 2006;20:882-887.

13. Monteiro ML, Leal BC, Moura FC, Vessani RM, Medeiros FA. Comparison of retinal nerve fibre layer measurements using optical coherence tomography versions 1 and 3 in eyes with band atrophy of the optic nerve and normal controls. Eye (Lond) 2007;21:16-22.

14. de Seze J, Blanc F, Jeanjean L, et al. Optical coherence tomography in neuromyelitis optica. Arch Neurol 2008:65:920-923.
15. Pueyo V, Martin J, Fernandez J, et al. Axonal loss in the retinal nerve fiber layer in patients with multiple sclerosis. Mult Scler 2008;14:609-614.

16. Henderson AP, Trip SA, Schlottmann PG, et al. An investigation of the retinal nerve fibre layer in progressive multiple sclerosis using optical coherence tomography. Brain 2008;131:277-287.

17. Ratchford JN, Quigg ME, Conger A, et al. Optical coherence tomography helps differentiate neuromyelitis optica and MS optic neuropathies. Neurology 2009;73:302-308.

18. Wingerchuk DM, Lennon VA, Pittock SJ, Lucchinetti CF, Weinshenker BG. Revised diagnostic criteria for neuromyelitis optica. Neurology 2006;66: 1485-1489.

19. Cree BA, Lamb S, Morgan K, Chen A, Waubant E, Genain C. An open label study of the effects of rituximab in neuromyelitis optica. Neurology 2005;64: 1270-1272.

20. Mandler RN, Ahmed W, Dencoff JE. Devic's neuromyelitis optica: a prospective study of seven patients treated with prednisone and azathioprine. Neurology 1998;51:1219-1220

21. Papeix C, Vidal JS, de Seze J, et al. Immunosuppressive therapy is more effective than interferon in neuromyelitis optica. Mult Scler 2007;13:256-259.

22. Costa-Cunha LV, Cunha LP, Malta RF, Monteiro ML. Comparison of Fourierdomain and time-domain optical coherence tomography in the detection of band atrophy of the optic nerve. Am J Ophthalmol 2009;147:56-63 e52.

23. Frohman E, Costello F, Zivadinov R, et al. Optical coherence tomography in multiple sclerosis. Lancet Neurol 2006;5:853-863.

24. Costello F, Hodge W, Pan Yl, Eggenberger E, Coupland S, Kardon RH. Tracking retinal nerve fiber layer loss after optic neuritis: a prospective study using optical coherence tomography. Mult Scler 2008;14:893-905.

25. Kallenbach K, Frederiksen J. Optical coherence tomography in optic neuritis and multiple sclerosis: a review. Eur J Neurol 2007;14:841-849.

26. Sepulcre J, Murie-Fernandez M, Salinas-Alaman A, Garcia-Layana A, Bejarano B, Villoslada P. Diagnostic accuracy of retinal abnormalities in predicting disease activity in MS. Neurology 2007;68:1488-1494.

27. Merle H, Olindo S, Donnio A, Richer R, Smadja D, Cabre P. Retinal peripapillary nerve fiber layer thickness in neuromyelitis optica. Invest Ophthalmol Vis Sci 2008;49:4412-4417.

28. Steel DH, Waldock A. Measurement of the retinal nerve fibre layer with scanning laser polarimetry in patients with previous demyelinating optic neuritis. J Neurol Neurosurg Psychiatry 1998;64:505-509.

29. Parisi V, Manni G, Spadaro M, et al. Correlation between morphological and functional retinal impairment in multiple sclerosis patients. Invest Ophthalmol Vis Sci 1999:40:2520-2527. 